TEMAS DE ACTUALIDAD

Rev Chil Salud Pública 2020,

Vol 24(1): 55-60

\section{SMALL IS NOT BEAUTIFUL: MINIMALIZACIÓN DE LA SALUD PÚBLICA ENFRENTE DE CORONAVIRUS}

\author{
SMALL IS NOT BEAUTIFUL: MINIMIZATION OF THE ROLE OF PUBLIC \\ HEALTH FACED WITH THE CORONAVIRUS
}

\section{INTRODUCCIÓN}

Es bueno que a uno lo sorprenda una época de reacción cuando está en una posición extrema.

Así se llega a una postura intermedia.

B. Brecht citado en el diario de W. Benjamin [1 , p.174-175]

El abordaje del brote de coronavirus ha sorprendido a la salud pública chilena y la ha obligado a echar mano de sus formas cuantitativas de manera extrema. Modelos predictivos basados en ecuaciones determinísticas, que en manos legas, se han transformado en un ejercicio reduccionista. De ahí la alarma y el miedo, dos herramientas propias de una ética de masas, pero lejos de la construcción de simbiosis y solidaridades.

Las tensiones intelectuales del brote, casi no han dado lugar a la aparición del otro gran fundamento de la salud pública actualmente existente, el gerencialismo gestionador. Su silencio ha mostrado también esa especie de inutilidad salpicada de lugares comunes, de la mano de una incapacidad para comprender los problemas locales en su dimensión territorial. Hay varias dimensiones del brote que una salud pública con más ambiciones intelectuales, podría ayudar a entender, para producir un pensamiento más sereno, pero no menos urgente.

Contra ese minimalismo respondo a la invitación de Revista Chilena de Salud Pública.

\section{CORONAVIRUS COMO OBJETO CIENTÍFICO}

La aparición de conglomerados de casos de enfermos con perfil y circunstancias inesperadas, en lugar y tiempo acotados, genera la identidad del brote. La retrospectiva analítica posterior, a menudo revela que el agente, la enfermedad y los enfermos ya existían previamente, por meses, años o décadas.

Su aparición como un patrón nosológico distinguible responde a condiciones muchas veces azarosas, a un cierto tipo de comunicación médica y por supuesto, a la capacidad para diferenciar en el ruido de fondo de la repetición, un objeto recortable y diferenciable.

La identificación del conglomerado está asociada a un intercambio en una red y al establecimiento de una comunidad científica. En VIH fue el CDC a través de sus reportes MMWR un factor clave en producir ese conglomerado y en el caso de Hanta, la conversación entre Bruce Tempest y sus colegas del Indian Health Service ${ }^{2}$.

La operación científica para aislar un agente y probar la ocurrencia de los postulados de Koch, para asignar la monocausalidad del agente no es tampoco tarea sencilla. Requiere destrezas detectivescas avanzadas y un poderoso laboratorio. En el
Yuri Carvajal Bañados Editor de Cuadernos Médico 
caso de legionella, en unos años 70 marcados por la toxicidad química, una vez agotado el primer trabajo de microscopía, inmunofluorescencia y cultivos clásicos, el agente fue explorado por cromatografía y espectrometría de masas, buscando moléculas de síntesis. Sólo un paciente trabajo de recuperación de muestras de anatomía patológica, inyección en huevos y prueba en cuyes y no en roedores, permitieron la identificación del agente.

La historia de VIH es también una dura tensión colaborativa entre los equipos de Gallo y Montagnier, en la persecución de la hipótesis de una variante HTLV por el equipo norteamericano versus la idea de un virus lento LAV por el equipo del Instituto Pasteur. La declaración conjunta Chirac Reagan en marzo de 1987 que ordenó políticamente el caso, da cuenta de la enorme movilización de redes que la producción de un objeto científico requiere ${ }^{3,4}$.

En coronavirus, China ha logrado generar el mol- de de la identificación causal, poniendo un alto estándar técnico a su diagnóstico. La técnica de amplificación de material genético mediante la reacción en cadena de la polimerasa (PCR), para identificar secuencias de ARN en secreciones que identifican al COVID-19, se ha establecido como el patrón de la enfermedad.

Más que ver un brote por las cifras de enfermos o por un patrón nosólógico, asistimos a una esmerada búsqueda de la traza, el móvil inmutable o la referencia circulante, tan propia de los objetos científicos ${ }^{5}$. Cuando ese patrón se extiende a objetos técnicos, aparecen problemas. Casos asintomáticos, sospechosos contagiosos, recuperados contagiosos. Al usar como gold standard la PCR, las técnicas de identificación de proteínas virales o de Inmunoglobulinas $M$ o $G$ específicas, amplían el espectro de casos, pero también acentúan una confusión sorprendente: ¡ya no sabemos qué es un enfermo!

Tabla 1: Sensibilidad de Test Diagnóstico en los días posteriores al inicio síntomas. Adaptado de Zhao J et al. Antibody responses to SARS-CoV-2 in patients of novel coronavirus disease 2019 Clin Infect Dis. 2020 Mar 28

\begin{tabular}{lccc}
\hline & 1-7 días & 8-14 días & 15-39días \\
\hline RNA por PCRs & $67 \%$ & $54 \%$ & $45 \%$ \\
Anticuerpos Totales & $38 \%$ & $90 \%$ & $100 \%$ \\
$\lg M$ & $29 \%$ & $73 \%$ & $94 \%$ \\
$\lg \mathrm{l}$ & $19 \%$ & $54 \%$ & $80 \%$ \\
\hline
\end{tabular}

\section{CORONAVIRUS COMO OBJETO TÉCNICO}

Y es que pasar desde un objeto científico a un objeto técnico, implica transitar por modos de existencia distintos $^{6,7}$. Los objetos técnicos no poseen el mismo estatus que los objetos científicos. La tecnicidad de la medicina hace gala de su pragmatismo, así deba vulnerar la trazabilidad de su objeto. Neutropenia febril por ejemplo es una entidad que llama a la acción terapeútica sin identificación del agente causal.

El objeto técnico es muchísimo más maleable, se modifica en el uso y se adapta localmente. Su característica es resolver el problema que lo constituye ${ }^{8,9}$.

Sostengo que la salud pública en manos de las SEREMI, de la oleada gestión que ha impregnado la disciplina y del retroceso de la presencia de ciencias sociales entre nosotros, ha provocado un giro ptolomeico en la constitución del objeto brote, perdiendo sencillez, parsimonia y por supuesto efectividad.

Revestidos de un escepticismo extremo, estamos ante una verdadera implosión de las cifras: ampliamente cuestionadas, inestables, heurísticamente pobres. Una definición de casos comandada por la clínica y por la tecnicidad debería constituir el caso coronavirus como una nosología local, territorializada, moldeada por el saber local y por las formas colectivas de existencia, con un curso a explorar, un objeto a conocer y no como una importación directa de Wuhan, universal y fija. Esto implica conocer la evolución clínica de los casos en los distintos centros locales, así como los factores de riesgo y sus pronósticos. Las formas de presentación y el curso del brote no han sido los mismos, ni siquiera en el país, región o comuna. Construir esas formas es tarea de los equipos locales con perspectiva colectiva. 


\section{APLANAR LA CURVA}

-Es la consigna - respondió el farolero.

- No comprendo - dijo el principito.

-No hay nada que comprender - dijo el farolero.

A de Saint-Exupéry. El Principito.

Aplanar la curva ha sido la consigna. Una sentencia que ha permitido un movimiento sincronizado, implementado rápido y sin debate, para obtener la acción de muchos, el encierro, mascarillas. Sin duda hay un aspecto de cooperación, en la medida en que todos se sienten parten de una tarea colectiva.

Para eso se ha congregado a trabajar en un objeto colectivo, la curva epidémica y en una tarea que requiere el concurso de todos. Un objeto ficcional, narrativo, toma la forma de un objeto científico y técnico.

Sostengo que los años de masivo aleccionamiento con las curvas de oferta y demanda, como agregación colectiva a partir de decisiones individuales, que producen un efecto como si una mano invisible los trazara, pavimentaron el camino para que la narrativa de aplanar la curva fuera tan exitosa.

Entender cómo se construyen estos objetos híbridos permite un uso más prudente. Las curvas están cargadas de supuesto y los datos que las ensamblan son bastante más frágiles e inestables que lo que el sentido común cree. No son objetos independientes, universales y permanentes, sino pequeños nodos que condensan episodios, circunstancias, organizaciones. Poseen una historia, están impregnados de los lugares que le dan nacimiento y vida, dependen de los espacios clínicos y de los sistemas de producción y registro de datos. No hay una sola y misma curvas. Los R0 calculados son inestables, condensan casos contados de forma poco sistemática, exámenes tomados con criterios distintos, comunas con casos excepcionales junto a comunas con brotes.

La avalancha de pronosticadores de muertes como ejercicio primordial de una nueva práctica de salud pública, ha colapsado en el mes de abril. Recuerdo haber leído el pronóstico de un biólogo matemático que aseguraba la ocurrencia de diez mil muertos en abril. Una cifra que sobrepasa todas las defunciones de un mes normal.

Por supuesto que es fácil decir que han sido las medidas tomadas las que evitaron ese pronóstico. No existe un contrafactual pues en ningún país el brote se ha desarrollado libre de acciones colectivas y de gobierno. La deriva de las cifras se basa en conductas asociativas, conectadas, imitadas, articuladas. No hay ningún resultado desprovisto de intervención. Ese olvido expresa agudamente el olvido de la reflexividad en la salud pública, de la consideración de la agencia del investigador y de los ámbitos colectivos, sobre el objeto investigado.

La pandemia es un objeto de las naturculturas, una emergencia que liquida la división moderna entre naturaleza y sociedad. Lo que este brote marca con crudeza es el colapso de esa separación. Si la salud pública cree poder observar fenómenos naturales, no sólo ve un pedazo de lo que ocurre enfrente de sus narices. Lisa y Ilanamente no logra ver lo que tiene enfrente.

\section{LA HISTORIA DE LAS ENFERMEDADES TRANSMISIBLES LOCALES}

Para una mejor comprensión de ese nudo de aspectos que constituyen un brote, nada mejor que las lecciones de los historiadores de las pestes. En esos estudios retrospectivos de casos se puede ver que estos fenómenos colectivos son un paño sin costura, en que lo cultural y lo biológico son casi indistinguibles, porque con la distancia de siglos, lo biológico se nos revela como intensamente cultural.

La reconstrucción actual del gran aniquilamiento originario en la conquista nos muestra que la potencia destructiva de la viruela no es un asunto exclusivamente inmune. La domesticación de animales, un fenómeno marcadamente cultural, es la causa de la inmunidad de los conquistadores y la desprotección de los conquistados ${ }^{10}$. Pero las hambrunas, la destrucción de sus siembras, el colapso moral provocado por la esclavitud forzada, son también factores de labilidad. ¿Biológico o social? Creo que la pregunta misma no tiene sentido.

Esa historia local de las enfermedades transmisibles es parte del saber en salud pública. La historia de la viruela que nos narra, es un ejemplo dramático de las cifras y proporciones del aniquilamiento colonial originario:

...e yendo este testigo a visitar unos indios que tenia en encomienda del gobernador don Pedro de Valdivia que eran casi 800 casas, halló haberse muerto todos los más indios de ellas e no halló vivo cien indios ...que en el repartimiento que había 3.000 indios no quedaron 200 ...que donde había un millón de indios no quedaron sino seis mil: tantos fueron los muertos que no parecía por todos aquellos campos persona alguna, y en re- 
partimiento que había mas de doce mil indios no quedaron treinta ... ${ }^{12}$

A esta aguda crisis colonial, le siguió un camino más o menos rampante de brotes coloniales. La república supo reducir finalmente a pueblos a los indios (reducciones) y producir ese sorprendente anidamiento de transmisibles en lugares de confinamiento como Isla Dawson o la Candelaria para Kawshkar, Selknam y Yaganes.
Lecciones para el brote actual en hospitales, cárceles, asilos de ancianos. Las escuela y fábricas se han salvado de la enumeración foucaultiana ${ }^{13}$. Las primeras por la suspensión de clases y tal vez, porque no se trata de una enfermedad tan agresiva. Las segundas, porque casi ya no existen. Historizar los brotes es darles su debida localidad y temporalidad, estudiarlos como casos, más que como series. Apreciar las lecciones de las invenciones locales, de las identificaciones locales y de las producciones situadas de saber.

Tabla 2: Principales brotes epidémicos en América Latina, 1519-1633 Adaptado de Noble David Cook Epidemias y Dinámica geográfica. En Historia General de América Latina II. El primer contacto y la formación de sociedades. Unesco/Trotta, Madrid, 2007.

\begin{tabular}{llll}
\hline América Central & & América Andina & \\
\hline $1519-1521$ & Viruela & $1524-1528$ & Viruela \\
$1531-1534$ & Sarampión & $1531-1533$ & Sarampión \\
1545 & Tifus, peste neumónica, paperas & 1546 & Tifus, peste neumónica \\
1550 & Paperas & & \\
$1559-1563$ & Sarampión, paperas, gripe, difteria & $1557-1562$ & Viruela, sarampión, gripe \\
$1576-1580$ & Tifus, viruela, sarampión, paperas & $1585-1591$ & Rifus, viruela, sarampión \\
1595 & Sarampión & 1597 & Sarampión \\
1604 & Sarampión, tifus, paperas & 1606 & Difteria \\
$1613-1614$ & Viruela, sarampión & $1611-1614$ & Sarampión, tifus, difteria \\
& & 1618 & Sarampión \\
\hline $1613-1632$ & Tifus & $1630-1633$ & Tifus \\
\hline
\end{tabular}

Tabla 3: Regalos mortíferos de nuestros amigos los animales, tomado de [14, p. 239].

\begin{tabular}{ll}
\hline Enfermedad humana & Animal con el patógeno más relacionado \\
\hline Sarampión & Ganado vacuno (tifus bovino) \\
Tuberculosis & Ganado vacuno \\
Viruela & Ganado vacuna (vacuna) u otros animales con virus relacionados \\
Gripe & Cerdos y patos \\
Tos ferina & Cerdos, perros \\
Malaria & Aves (igallinas y patos?) \\
\hline
\end{tabular}




\section{LA SALUD PÚBLICA COMO EL RESIDUO NO EXPLICADO POR LA CLÍNICA}

Desde la reforma de salud hemos llegado a mirar la salud pública como si fuera un resto, un saldo, la variabilidad de los hechos no explicados por la clínica. Es por eso que tenemos dos subsecretarías y a nivel local, servicios de salud y seremis.

Todo lo que no ocurre en la clínica (hoy se Ilaman dispositivos) vendría siendo salud pública. El brote ha mostrado el fracaso de esa noción. Los agentes encargados de hacer la vigilancia y revisar la evolución de los contactos, están aislados de los casos hospitalizados y del seguimiento de la expresión y evolución clínica de los enfermos.

Este brote debería servirnos para recuperar la unidad perdida, retomando las lecciones de Chillán 1939:

la experiencia de fusión de los servicios médicos asistenciales y sanitarios en las zonas afectadas por el terremoto, pese a las circunstancias extraordinariamente difíciles en que han comenzado y a los defectos de organización que ha tenido, ha sido una empresa coronada por el éxito [15, p.155].

La promesa de que la inteligencia sanitaria se iba a concentrar en las seremis no se ha cumplido, por decirlo de manera elegante. De manera ruda, no existe práctica de salud pública hoy en las instituciones oficiales. Hay gerencialismo, comunicación, oficinas y computadores.

\section{ÉTICA EN TIEMPOS DE BROTES}

En los matutinos reportes del MINSAL se ha empezado a hablar en voz alta de limitación del esfuerzo terapéutico o cuidados proporcionales. Han entrado entonces por puerta ancha al brote debates que se han mantenido en reserva o en voz baja. Si ya han sido reconocidas como prácticas reales y legítimas, es el momento en que se regulen estas prácticas. No para coartarlas y restringirlas, sino para reconocerlas, darle una debida institucionalidad y formalidad, hacerlas visibles y evaluables.

Es sorprendente que, a los propios firmantes de la Ley de deberes y derechos, la vida les hubiera devuelto que eso de no acelerar artificialmente la muerte, no es más que una falacia. Morir no es un evento libre de artificialidad.

La privacidad de los datos también ha sido víctima precoz del brote. Sólo que no en la forma en que la salud pública lo requiere.

\section{UNA SALUD PÚBLICA ECOLÓGICA}

\author{
Esto puede darse una vez, no volverá a pasar \\ $\left[{ }^{1}, p .164\right]$
}

Sé que el Ministro de Salud tiene una cultura biológica no acostumbrada en autoridades previas de la cartera, con la excepción de Jiménez de la Jara. Recuerdo haberlo escuchado inaugurar un congreso de epidemiología con una apasionada charla darwiniana spencereana, difícil de contra replicar.

Sostengo que tener una cultura biológica es de gran utilidad en salud pública. Sólo que no hay un solo Darwin bajo el cielo. Hay también uno botánico y lumbricultor que difiere del evolucionista de la selección natural, aunque ambos viajaron en el Beagle. El mar turbulento de esta crisis alimenta más una cultura biológica próxima al eco-evo-devo que a El origen de las especies.

Si me apuraran un poco más diría que hay un Darwin equiparable a Lamarck y Haeckel, los dos grandes fundadores de la ecología. Lamarck propuso mirar la tierra como la conjunción de tres esferas y su propuesta de la biología como nueva ciencia, cobra sentido pleno en esa perspectiva:

Una física íntegra de la Tierra debería incluir todas las consideraciones esenciales tanto sobre la atmósfera de la tierra, como acerca de las características y los cambios continuos de la corteza, y finalmente, sobre el origen y desarrollo de los seres vivos. Lógicamente, esas consideraciones dividen a la física de la tierra en tres partes esenciales, siendo la primera de ella una teoría de la atmósfera, o metereología; la segunda, una teoría de la corteza de la tierra, o hidrogeología; y la tercera, una teoría de los organismos vivos o biología (Hidrogeología [1801] citado en [16]).

A lo que quiero apuntar es a la salud pública como una comprensión ecológica de los fenómenos no sólo biológicos, sino colectivos.

One Health, emergencia climática, antropoceno, Gaia, son otros tantos objetos narrativos para intentar ensanchar el horizonte conceptual al que nos ha reducido esta oleada avasalladora de lo cuantitativo. Ojalá recordáramos que la expresión epidemias aparece por primera vez en un texto sin ecuaciones ni números. Pensar la salud como una ecología, como una sociología afincada en lo biológico, en un sentido contrapuesto al proyecto de E. O. Wilson.

Así haríamos una salud pública verdaderamente 
colectiva. No es mucho pedir, sino simplemente dejar de replegarnos en números y gestionalismo, y movernos a la capacidad de generar métodos y echar mano del bagaje intelectual adecuado a nuestro objeto de estudio. Seguir poniendo los métodos delante del problema, en tiempos de incertidumbres, irreducciones e indeterminaciones.

\section{REFERENCIAS}

1. Benjamin W. Materiales para un autorretrato. Buenos Aires: FCE; 2017.

2. Garrett L. The Coming Plague. Newly emerging diseases in a world out of balance. New York: Penguin Books; 1995.

3. Grmek M. Historia del SIDA. México: Siglo Veintiuno Editores; 2004 [1989].

4. Fleck L. Gênese e Desenvolvimento de um Fato Científico. Belo Horizonte: FABREFACTUM editora; 2010.

5. Latour B, Woolgar S. La vie de laboratoire. La production des faits scientifiques. Paris: Éditions La Découverte; 2008[1979].

6. Latour B. Investigación sobre los modos de existencia. Una antropología de los modernos. Buenos Aires: Paidós; 2013.

7. Lapoujade D. Las existencias menores. Buenos Aires: Cactus; 2018.
8. Latour B. La esperanza de Pandora. Ensayos sobre la realidad de los estudios de ciencia. Barcelona: Gedisa Editorial; 2001 [1999].

9. Latour B. Aramis, ou I amour des techniques. Paris: Éditions La Découverte; 1992.

10. Crosby A. Ecological Imperialism. 2nd ed. New York: Cambridge University Press; 2015.

11. Ferrer L. Historia General de Medicina en Chile. Imp. Talca, de J. Martin Garrido C.-3 Oriente, 653 661; 1904.

12. Laval E. Desarrollo de la Viruela en Chile desde la Conquista hasta 1825, Grajales. Anales Chilenos de Historia de la Medicina. 1967-1968;1(1):203-276.

13. Foucault M. vigilar y castigar. nacimiento de la prisión. Buenos Aires: Siglo Veinteiuno Editores; 200[1975].

14. Diamond J. Armas, gérmenes y acero. Breve historia de la humanidad en los últimos trece mil años. Barcelona: Penguin Random House; 2016.

15. Allende S. La Realidad Médico-Social Chilena. Santiago: Ministerio de Salubridad; 1939.

16. Jordanova L. Lamarck. México: Fondo de Cultura Económica; 1990[1984]. 